\title{
A novel model to predict positive prostate biopsy based on serum androgen level
}

\author{
Takeshi Ujike1, Motohide Uemura1,2, Atsunari Kawashima', Akira Nagahara', Kazutoshi Fujita', Yasushi Miyagawa1 \\ and Norio Nonomura' \\ 1Department of Urology, Osaka University Graduate School of Medicine, Suita, Osaka, Japan \\ 2Department of Therapeutic Urologic Oncology, Osaka University Graduate School of Medicine, Suita, Osaka, Japan \\ Correspondence should be addressed to M Uemura: uemura@uro.med.osaka-u.ac.jp
}

\begin{abstract}
Circulating levels of prostate-specific antigen (PSA) and testosterone are widely used for the detection of prostate cancer prior to prostate biopsy; however, both remain controversial. Effective screening strategies based on quantitative factors could help avoid unnecessary biopsies. Here, we sought to clarify the predictive value of free testosterone (FT) vs total testosterone (TT) in identifying patients likely to have positive biopsies. This study aims to develop a novel model for predicting positive prostate biopsy based on serum androgen levels. This study included 253 Japanese patients who underwent prostate biopsy at our institution. TT and FT, \% FT (=FT/TT), age, PSA, prostate volume (PV) and PSA density (PSAD = PSA/PV) were assessed for association with prostate biopsy findings. The following results were obtained. Of 253 patients, $145(57.3 \%)$ had positive biopsies. Compared to the negative biopsy group, the positive biopsy group demonstrated higher age, PSA and PSAD but lower PV, FT and \%FT by univariate analysis. Multivariate logistic regression analysis indicated PSA, PSAD and \%FT were independent predictors of cancer detection. We developed a predictive model based on PSAD and $\% \mathrm{FT}$, for which the area under the curve was significantly greater than that of PSA ( 0.82 vs 0.66 ), a well-known predictor. Applying this analysis to the subset of patients with PSA $<10 \mathrm{ng} / \mathrm{mL}$ yielded similar results. We confirmed the utility of this model in another independent cohort of 88 patients. In conclusion, lower \%FT predicted a positive prostate biopsy. We constructed a predictive model based on \%FT and PSAD, which are easily obtained prior to biopsy.
\end{abstract}

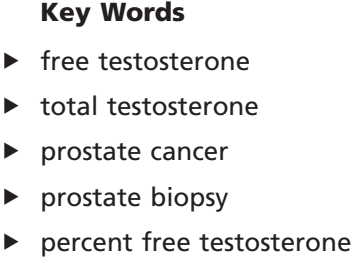

Endocrine-Related Cancer (2018) 25, 59-67

\section{Introduction}

Definitive diagnosis of prostate cancer depends on histopathological verification. Prostate biopsy is the only method for definitive diagnosis of prostate cancer. Prostate cancer is usually suspected on the basis of digital rectal examination (DRE) and/or elevated PSA; however, DRE findings have poor sensitivity, limited specificity and high inter-observer variability. According to EAU-ESTRO-SIOG guidelines on prostate cancer (version 2016) (Mottet et al. 2016), PSA is a better predictor of prostate cancer than either DRE or transrectal ultrasonography (TRUS).

Although elevated PSA is the most frequent indication for prostate biopsy, mainly because of its high sensitivity, PSA-based diagnostics also have a low specificity, and thus, likely contribute to the increasing frequency of
(C) 2018 The authors Published by Bioscientifica Ltd. Printed in Great Britain

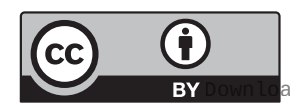

This work is licensed under a Creative Commons Attribution 4.0 International License. 
unnecessary biopsies, which should be avoided. Therefore, several clinical factors have been investigated as alternative indicators. Recently, there has been significant interest in developing multiparametric magnetic resonance imaging (mpMRI) to aid in the diagnosis of prostate cancer (Feng et al. 2015, Bergdahl et al. 2016); however, it remains unclear whether mpMRI could aid in informing decisions regarding prostate biopsy. EAU-ESTRO-SIOG guidelines (Mottet et al. 2016) pointed out that mpMRI has limitations similar to those that beset DRE and TRUS, that is, it is subject to inter-observer variability and the heterogeneity in the definitions of positive and negative examinations. In order to reduce harm by avoiding unnecessary biopsies, there is a need for a more effective screening strategy based on quantitative factors obtained before prostate biopsy.

Since the pioneering report of Huggins and coworkers regarding the relationship between prostate cancer progression and androgen in the 1940s (Huggins et al. 1942), many studies have assessed the utility of serum androgen measurement (total testosterone (TT), free testosterone (FT)) in prostate cancer screening (Klap et al. 2015, Regis et al. 2015). While some studies assessed various parameters calculated by absolute androgen concentrations, for example, the ratio of PSA to TT, or of PSA to FT, these associations remain controversial (Porcaro et al. 2010, Albisinni et al. 2012, Regis et al. 2015).

In this study, we focused on not only absolute androgen levels, but also the relative concentration of FT to TT (\%FT). In the first step, we investigated whether TT and FT values can be predictive biomarkers for prostate cancer detection upon prostate biopsy in the Japanese population. Next, we established a novel predictive model, using quantitative factors that can be easily obtained prior to prostate biopsy.

\section{Materials and methods}

\section{Patients}

This study included 253 patients who underwent initial prostate biopsy in Osaka University Hospital from July 2014 to September 2016. The indication for prostate biopsy was suspicion of prostate cancer on the basis of serum PSA elevation and/or DRE findings. None of these patients underwent testosterone therapy. All patients underwent transrectal ultrasound-guided systemic 12-core prostate needle biopsy. Targeted biopsies were conducted for suspicious lesions. To confirm our results in another independent cohort, we recruited 88 patients who underwent prostate biopsy from October 2016 to June 2017 in our institution. This study was approved by the Osaka University Hospital Institutional Review Board.

\section{Clinical data collected}

The following clinical data were collected retrospectively from the medical records at Osaka University Hospital: histopathological findings of prostate biopsy, age, PSA, PV, PSAD, values of serum TT and FT. \%FT was obtained by dividing the two concentrations (FT/TT), after converting free testosterone values to $\mathrm{ng} / \mathrm{mL}$. PV was measured by TRUS.

\section{Blood samples}

Blood samples were obtained between $08: 00 \mathrm{~h}$ and 10:00 $\mathrm{h}$ to assess TT and FT levels according to the Endocrine Society's guidelines (Rosner et al. 2007). Serum TT was measured by chemiluminescent immunoassay (using Lumipulse Presto Testosterone, Fujirebio Inc., Japan). Serum FT was measured by radioimmunoassay (using Free Testosterone RIA kit, Sceti Medical Labo K.K., Japan).

\section{Statistical methods}

Results were expressed as the median (range) for continuous variables. Univariate analysis was performed by the Mann-Whitney $U$ test. Univariate and multivariate logistic regression analysis were performed to determine the correlation between prostate cancer detection and clinical factors (age, PSA, PV, PSAD, TT, FT, \%FT). As the variable PSAD is made up of PSA and PV, PV was removed from the models. The predicted probability of a positive biopsy result was estimated as $P=1 /\left(1+e^{-x}\right)$. Logistic regression yields a score $(X)$, where $X$ is $\beta_{0}+\beta_{1} X_{1}+\beta_{2} X_{2}+\beta_{3} X_{3} \ldots$, which is a linear combination of the predictors $\left(X_{1}, X_{2}\right.$, $\left.X_{3} \ldots\right)$ in the model. The model coefficients $\left(\beta_{0}, \beta_{1}, \beta_{2}\right)$ were chosen to optimize the ability to predict a positive biopsy result. A nomogram predicting the probability of prostate cancer was constructed based on this formula. The new diagnostic model obtained was evaluated for diagnostic ability using the receiver-operator characteristics (ROC) curve analysis. To determine significant differences in the area under the ROC curve (AUC) compared to other existing factors, the chi-square test was used. Statistical significance was considered as $P<0.05$. All data analyses were performed with JMP, ver.10 (SAS Institute Inc., Cary, NC, USA).

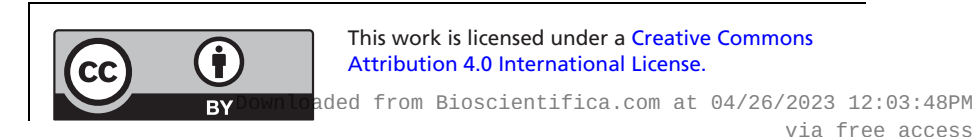


Table 1 Patient characteristics of all cases.

\begin{tabular}{|c|c|c|c|}
\hline Variables & Negative biopsy & Positive biopsy & $P$ value \\
\hline Number & 108 & 145 & \\
\hline ge (years) & $67.5(35-79)$ & & 0.0001 \\
\hline $\begin{array}{l}\text { PSA } \\
\text { (ng/mL) }\end{array}$ & $6.90(1.06-27.29)$ & $9.67(2.77-3534.41)$ & \\
\hline & & & \\
\hline $\begin{array}{l}\mathrm{PSAD}( \\
\mathrm{mL} / \mathrm{cr}\end{array}$ & & & \\
\hline$n L)$ & & & \\
\hline & & & \\
\hline$\%$ FT (\%) & $0.245(0.081-1.26)$ & $0.196(0.019-0.481)$ & $<0.0001$ \\
\hline
\end{tabular}

Median (range). $P$ value was calculated by Mann-Whitney $U$ test. $\mathrm{FT}$, free testosterone; \% FT, percent free testosterone; PSA, prostatespecific antigen; PSAD, PSA density; PV, prostate volume; TT, total testosterone.

\section{Results}

\section{Analysis in the entire cohort}

Patient characteristics are summarized in Table 1. Among 253 patients, 145 patients (57.3\%) had a positive biopsy, and 108 patients (42.7\%) had a negative biopsy. In univariate analysis, age, PSA and PSAD were significantly higher in the positive biopsy group compared with the negative biopsy group. However, PV, FT and \%FT were significantly lower in the positive biopsy group compared with the negative biopsy group. TT was not significantly different between two groups. Multivariate logistic regression analysis revealed that PSA, PSAD and \%FT were independent predictors for incidence of prostate cancer upon prostate biopsy $(P<0.05)$, whereas age and FT were not significant (Table 2 ).

Subsequently, from the result of multivariate logistic regression analysis using PSAD and \%FT, we created a predictive model for the probability of detecting prostate cancer upon biopsy as represented by the following formula: $P=1 /\left(1+e^{-x}\right) X=0.198-7.96 \times \% \mathrm{FT}+5.85 \times \mathrm{PSAD}$.
Using this predictive model (PSAD-\%FT model), the AUC for the probability of detecting prostate cancer in all patients was 0.824 , while the AUC for PSA, \%FT and PSAD were $0.662,0.676$ and 0.786 , respectively (Fig. 1). The AUC for PSAD-\%FT model was statistically greater than PSA $(P<0.0001)$ (Fig. $2 A)$ and PSAD $(P=0.018)$. The sensitivity and specificity of PSAD-\%FT model was $74.5 \%$ and $79.7 \%$, respectively.

Analysis in the subgroup of patients with a PSA level under $10 \mathrm{ng} / \mathrm{mL}$

We then repeated this analysis among the subset of patients with PSA $<10 \mathrm{ng} / \mathrm{mL}$. Among these 156 patients, 75 patients $(45.5 \%)$ had a positive biopsy and 81 patients $(54.5 \%)$ had a negative biopsy. These patient characteristics are summarized in Table 3. In univariate analysis, PSAD was significantly higher in the positive biopsy group compared with the negative biopsy group, while PV, FT and \%FT were significantly lower in the positive biopsy group compared with the negative biopsy group. Multivariate logistic regression analysis revealed that PSAD and \%FT were independent predictors of outcome of prostate biopsy $(P<0.05)$ (Table 4$)$.

Similar to the previous analyses, we created a predictive model by combining these two predictors (PSAD and $\%$ FT) for this subgroup analysis based on the result of multivariate logistic regression analysis using PSAD and $\%$ FT. The following model for predicting the probability of detecting prostate cancer by prostate biopsy was obtained: $P=1 /\left(1+e^{-x}\right) \quad X=0.650-8.13 \times \% \mathrm{FT}+4.61 \times \mathrm{PSAD} . \quad$ Using this predictive model (PSAD-\%FT model), the AUC for the probability of detecting prostate cancer was 0.733 , while the AUC for PSA, \%FT and PSAD were 0.543, 0.681 and 0.670, respectively (Fig. 3). The AUC for PSAD-\%FT model was greater than that for PSA $(P=0.0044)$ and PSAD

Table 2 Logistic analysis of variables associated with cancer detection in all cases.

\begin{tabular}{|c|c|c|c|c|c|c|}
\hline \multirow[b]{2}{*}{ Variables } & \multicolumn{3}{|c|}{ Univariate } & \multicolumn{3}{|c|}{ Multivariate } \\
\hline & OR & $95 \% \mathrm{Cl}$ & $P$ value & OR & $95 \% \mathrm{Cl}$ & $P$ value \\
\hline Age & 1.08 & $1.04-1.13$ & $<0.0001$ & 1.02 & $0.97-1.08$ & 0.343 \\
\hline PSA & 1.09 & $1.05-1.14$ & $<0.0001$ & 0.93 & $0.90-1.00$ & 0.048 \\
\hline PV & 0.97 & $0.95-0.98$ & $<0.0001$ & & & \\
\hline PSAD 0.1 increase & 1.87 & $1.53-2.36$ & $<0.0001$ & 2.08 & $1.60-2.76$ & $<0.0001$ \\
\hline TT & 1.12 & $0.92-1.38$ & 0.274 & & & \\
\hline FT & 0.84 & $0.76-0.92$ & 0.0001 & 0.99 & $0.86-1.14$ & 0.917 \\
\hline$\%$ FT 0.01 increase & 0.92 & $0.89-0.96$ & $<0.0001$ & 0.93 & $0.89-0.98$ & 0.0042 \\
\hline
\end{tabular}

When treating PSAD and \%FT as continuous predictors, the odds ratio have been computed for a 0.1 increase in PSAD levels and a $0.01 \%$ increase in $\% \mathrm{FT}$ levels. $P$ value was calculated by likelihood ratio test.

$\mathrm{Cl}$, confidence interval; $\mathrm{FT}$, free testosterone; \%FT, percent free testosterone; OR, odds ratio; PSA, prostate-specific antigen; PSAD, PSA density; $\mathrm{PV}$, prostate volume; TT, total testosterone.

http://erc.endocrinology-journals.org https://doi.org/10.1530/ERC-17-0134
() 2018 The authors Published by Bioscientifica Ltd. Printed in Great Britain

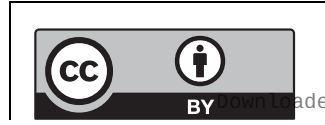

This work is licensed under a Creative Commons Attribution 4.0 International License. ed from Bioscientifica.com at $04 / 26 / 2023$ 12:03:48PM via free access 

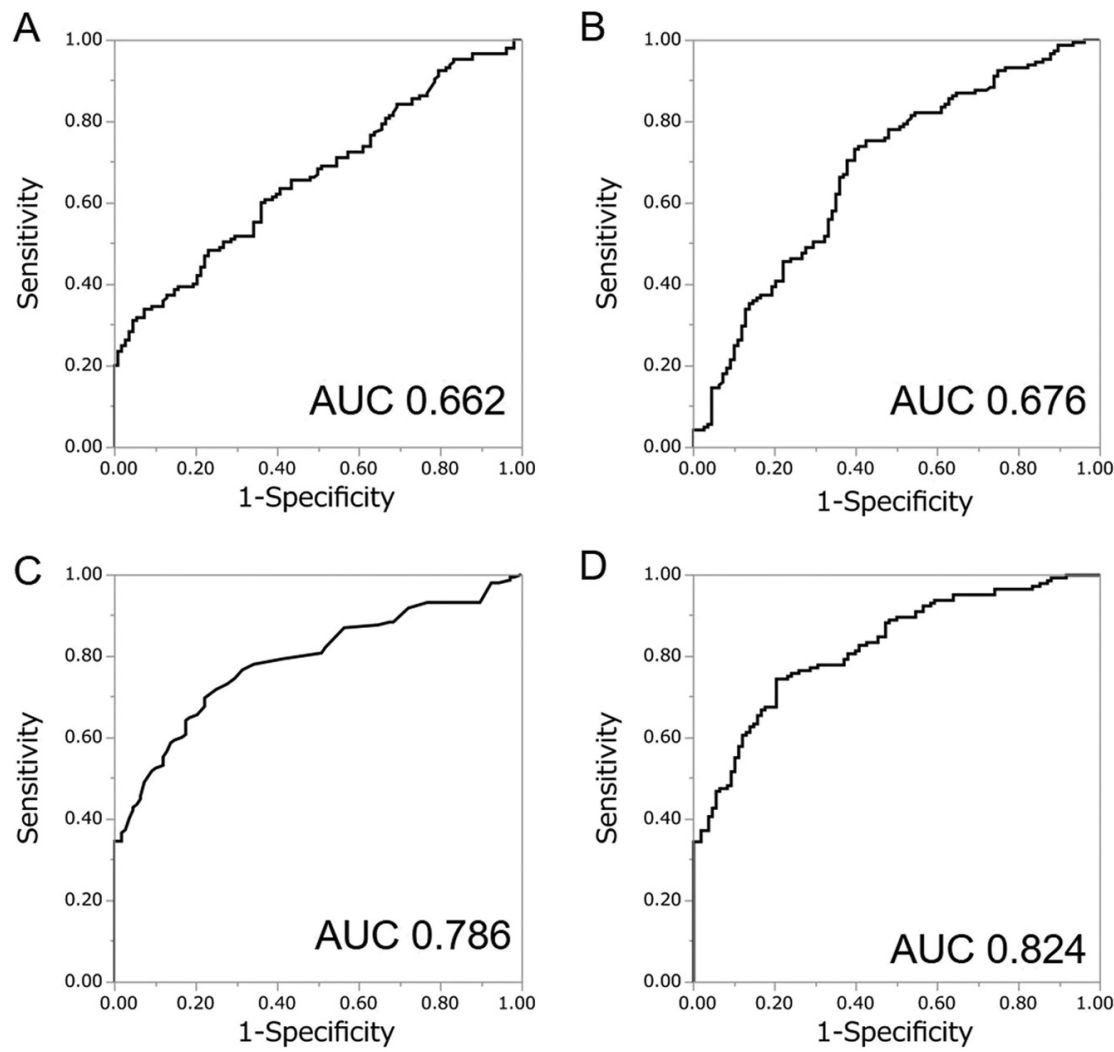

Figure 1

Receiver-operator characteristics (ROC) curves of the predicted probability of prostate cancer detection for all 253 patients by PSA (A), \%FT (B), PSAD (C) and PSAD-\%FT model (D).

$(P=0.06)$ (Fig. 2B). The sensitivity and specificity of this optimal model were $85.3 \%$ and $54.3 \%$, respectively.

\section{Validation in testing cohort}

Next, in order to confirm the utility of this model (PSAD-\%FT model), we applied it to 88 patients in an independent cohort.

Patient characteristics are summarized in Table 5. Among 88 patients, 48 patients (54.5\%) had a positive biopsy, and 40 patients (45.5\%) had a negative biopsy. In this cohort, ROC curve analysis was performed by applying the following predictive formula: $P=1 /\left(1+e^{-x}\right)$
$X=0.198-7.96 \times \% \mathrm{FT}+5.85 \times$ PSAD. Using this predictive model (PSAD-\%FT model), the AUC for the probability of detecting prostate cancer was 0.883. The AUC for PSAD$\%$ FT model was greater than that for PSA $(\mathrm{AUC}=0.704$, $P=0.0003$ ) (Fig. 4A) and PSAD (AUC=0.854, $P=0.286$ ).

In our testing cohort, we also added an analysis among the subset of patients with PSA $<10 \mathrm{ng} / \mathrm{mL}$. Patient characteristics are summarized in Table 6 . Among 59 patients, 26 patients (44.1\%) had a positive biopsy, and 33 patients (55.9\%) had a negative biopsy. In this cohort, ROC curve analysis was performed by applying the following predictive formula: $P=1 /\left(1+e^{-x}\right)$ $X=0.650-8.13 \times \% \mathrm{FT}+4.61 \times \mathrm{PSAD}$.
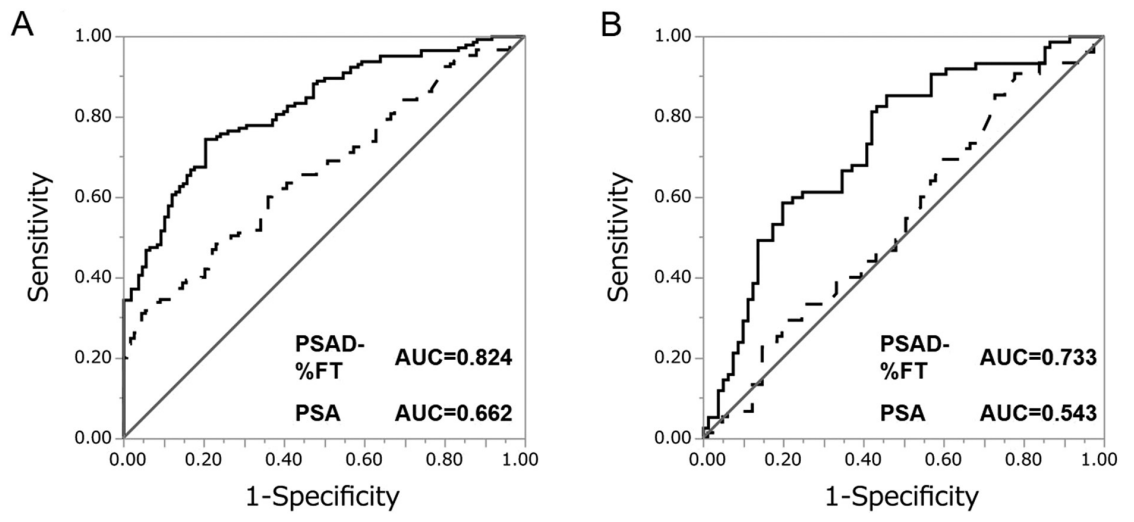

\section{Figure 2}

Receiver-operator characteristics (ROC) curves of the predicted probability of prostate cancer detection by the PSAD-\%FT model (solid curves) and PSA (dotted curves). (A) ROC curves for all 253 patients. (B) ROC curves for 156 patients with PSA levels under $10 \mathrm{ng} / \mathrm{mL}$. 
Table 3 Patient characteristics of 156 patients with PSA levels under $10 \mathrm{ng} / \mathrm{mL}$.

\begin{tabular}{|c|c|c|c|}
\hline Variables & Negative biopsy & Positive biopsy & $P$ value \\
\hline Number & 81 & 75 & \\
\hline Age (years) & $67(35-79)$ & $71(52-80)$ & 0.014 \\
\hline PSA (ng/mL) & $5.75(1.06-9.93)$ & $5.74(2.77-9.74)$ & 0.358 \\
\hline $\mathrm{PV}(\mathrm{mL})$ & $31(10.5-90)$ & $24(10-77)$ & 0.0004 \\
\hline $\begin{array}{l}\text { PSAD (ng/ } \\
\left.\mathrm{mL} / \mathrm{cm}^{3}\right)\end{array}$ & $0.19(0.05-0.52)$ & $0.27(0.05-0.65)$ & 0.0002 \\
\hline $\mathrm{TT}(\mathrm{ng} / \mathrm{mL})$ & $3.02(1.35-7.76)$ & $3.32(1.86-6.81)$ & 0.378 \\
\hline $\mathrm{FT}(\mathrm{pg} / \mathrm{mL})$ & $7.8(2.2-27.5)$ & $6.6(0.8-17.1)$ & 0.003 \\
\hline$\% \mathrm{FT}(\%)$ & $0.249(0.081-1.27)$ & $0.195(0.019-0.353)$ & $<0.0001$ \\
\hline
\end{tabular}

Median (range). $P$ value was calculated by Mann-Whitney $U$ test. $\mathrm{FT}$, free testosterone; \% FT, percent free testosterone; PSA, prostatespecific antigen; PSAD, PSA density; PV, prostate volume; TT, total testosterone.

Using this predictive model (PSAD-\%FT model), the AUC for the probability of detecting prostate cancer was 0.796. The AUC for PSAD-\%FT model was greater than that for PSA (AUC=0.607, $P=0.0114$ ) (Fig. 4B) and PSAD (AUC $=0.762, P=0.566$ ).

In summary, analysis of the validation cohort resulted in substantially the same findings as from the original cohort: in addition to higher PSAD, which is a well-known predictor, \%FT levels predict a positive biopsy for prostate cancer.

\section{Discussion}

After Huggins and coworkers reported that metastatic prostate cancer growth was suppressed by eliminating androgens via castration, it was believed for a long time that higher TT contributed to prostate cancer and caused rapid cancer growth (Huggins et al. 1942).

However, recent studies have demonstrated no relationship between TT levels and prostate cancer risk (Mohr et al. 2001, Yano et al. 2007, Morote et al. 2009,
Botelho et al. 2012). Yano and coworkers investigated the relationship between TT levels and positive biopsy among 420 patients and concluded that there was no significant difference in pretreatment TT among the positive and negative biopsy groups (Yano et al. 2007). Rather paradoxically, some studies reported a significant correlation between low levels of TT with increased prostate cancer risk or grade (Shin et al. 2010, Garcia-Cruz et al. 2012, Tu et al. 2017).

Shin and coworkers investigated prostate cancer risk on prostate biopsy according to TT level (Shin et al. 2010). In their study, 568 patients were enrolled and divided into two groups according to median TT level $(385 \mathrm{ng} / \mathrm{mL})$. They concluded that patients with lower levels of TT had a higher risk of prostate cancer in the Korean population.

Recently, active surveillance has become one of the most important treatment options for low-risk prostate cancer, but no firm criteria have been established to guide this decision. Some studies identified clinical factors associated with tumor upgrading in low-risk prostate cancer (Porcaro et al. 2016, 2017, Ferro et al. 2017). Ferro and coworkers and Porcaro and coworkers reported the usefulness of TT measurement in informing decisions regarding active surveillance, but did not come to definitive conclusions (Ferro et al. 2017; Porcaro et al. 2017).

At the present time, correlation between serum TT level and prostate cancer risk is controversial. Clap and coworkers reviewed 45 articles that discussed TT and the subsequent risk of prostate cancer, concluding that the literature reports contradictory results: Of the 45 articles, 18 suggested low TT increases the risk of prostate cancer, 17 suggested high TT increases the risk and 10 showed no relationship (Clap et al. 2015). Much of this controversy appears to be based on conflicting study designs, definitions and methodologies. The review also

Table 4 Logistic analysis of variables associated with cancer detection in 156 patients with PSA levels under $10 \mathrm{ng} / \mathrm{mL}$.

\begin{tabular}{|c|c|c|c|c|c|c|}
\hline \multirow[b]{2}{*}{ Variables } & \multicolumn{3}{|c|}{ Univariate } & \multicolumn{3}{|c|}{ Multivariate } \\
\hline & OR & $95 \% \mathrm{Cl}$ & $P$ value & OR & $95 \% \mathrm{Cl}$ & $P$ value \\
\hline Age & 1.06 & $1.01-1.12$ & 0.014 & 1.03 & $0.98-1.10$ & 0.236 \\
\hline PSA & 1.07 & $0.91-1.26$ & 0.421 & & & \\
\hline PV & 0.96 & $0.94-0.97$ & 0.002 & & & \\
\hline PSAD 0.1 increase & 1.72 & $1.29-2.36$ & 0.0002 & 1.55 & $1.15-2.15$ & 0.004 \\
\hline TT & 1.08 & $0.83-1.42$ & 0.556 & & & \\
\hline FT & 0.84 & $0.73-0.94$ & 0.002 & 0.99 & $0.85-1.16$ & 0.930 \\
\hline \%FT 0.01 increase & 0.91 & $0.87-0.96$ & $<0.0001$ & 0.93 & $0.88-0.98$ & 0.009 \\
\hline
\end{tabular}

When treating PSAD and \%FT as continuous predictors, the odds ratio have been computed for a 0.1 increase in PSAD levels and a $0.01 \%$ increase in $\%$ FT levels. $P$ value was calculated by likelihood ratio test.

$\mathrm{Cl}$, confidence interval; $\mathrm{FT}$, free testosterone; \%FT, percent free testosterone; OR, odds ratio; PSA, prostate-specific antigen; PSAD, PSA density; PV prostate volume; TT, total testosterone.

http://erc.endocrinology-journals.org https://doi.org/10.1530/ERC-17-0134
() 2018 The authors Published by Bioscientifica Ltd. Printed in Great Britain

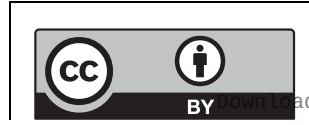

This work is licensed under a Creative Commons Attribution 4.0 International License. ded from Bioscientifica.com at 04/26/2023 12:03:48PM via free access 

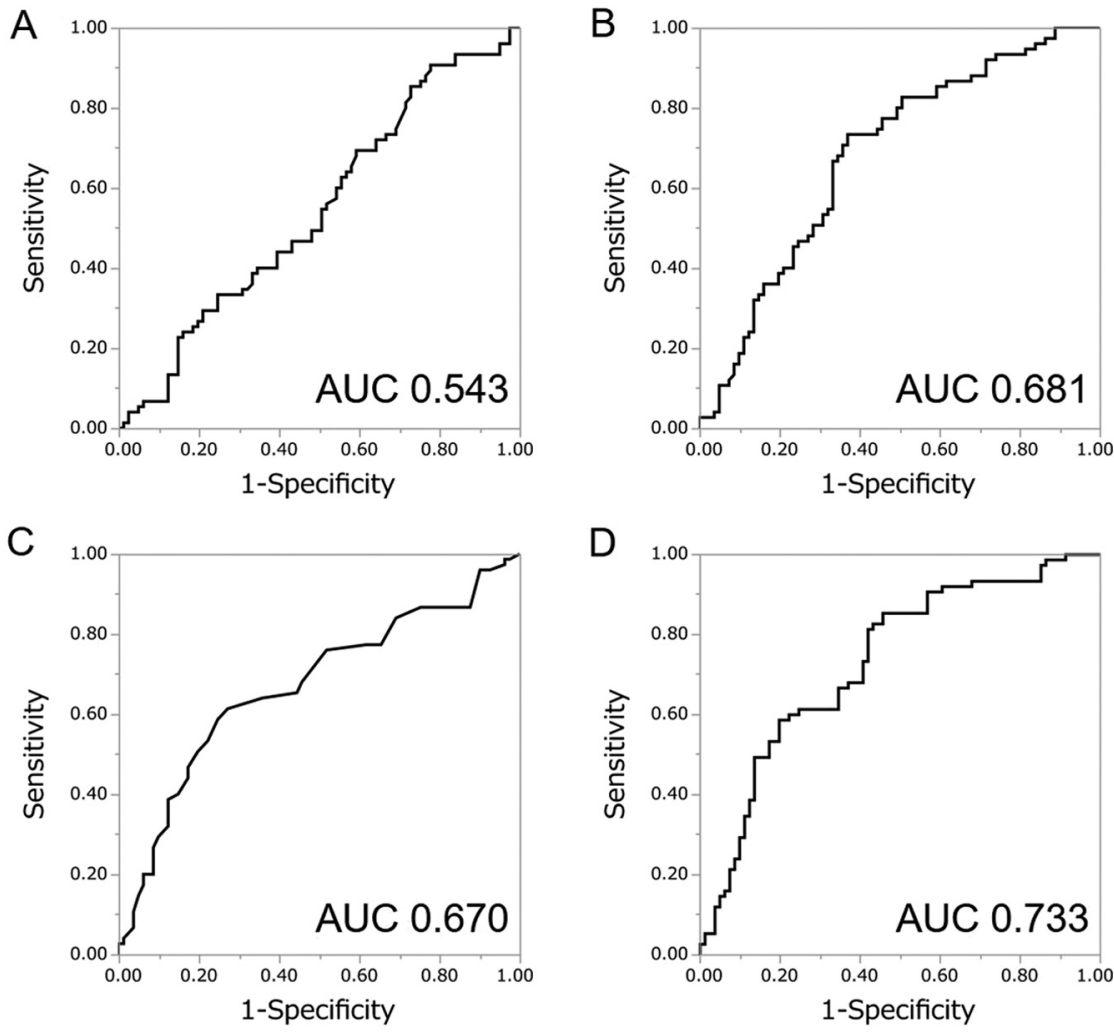

Figure 3

Receiver-operator characteristics (ROC) curves of the predicted probability of prostate cancer detection for 156 patients with PSA levels under $10 \mathrm{ng} / \mathrm{mL}$ by PSA (A), \%FT (B), PSAD (C) and PSAD-\%FT model (D).

pointed out that these conflicting results may stem from insufficient knowledge about the underlying physiology of prostate cancer and that the effective concentration of TT in prostate tissue must be considered.

In terms of endocrinology, much of the circulating TT in the blood is bound to protein and not available to cells. To investigate the relationship between androgens and prostate cancer risk, we focused on FT, which is bioavailable and a measurable component in TT. TT concentration refers to both bioavailable and nonbioavailable testosterone in the circulation. The term

Table 5 Patient characteristics in testing cohort.

\begin{tabular}{|c|c|c|c|}
\hline Variables & Negative biopsy & Positive biopsy & $P$ value \\
\hline Number & 40 & 48 & \\
\hline Age (years) & $69(50-81)$ & 72 (57-84) & 0.138 \\
\hline PSA (ng/mL) & $6.38(3.55-29.41)$ & $9.70(4.20-408)$ & 0.0011 \\
\hline $\mathrm{PV}(\mathrm{mL})$ & $35.6(17.3-139.8)$ & $26.0(12.2-72)$ & 0.0002 \\
\hline $\begin{array}{l}\text { PSAD (ng/ } \\
\left.\mathrm{mL} / \mathrm{cm}^{3}\right)\end{array}$ & $0.18(0.06-0.41)$ & $0.37(0.09-5.67)$ & $<0.0001$ \\
\hline TT (ng/mL) & $3.52(1.65-7.31)$ & $3.56(1.82-7.36)$ & 0.821 \\
\hline FT $(p g / m L)$ & $7.8(3.1-16.7)$ & $7.1(3.4-15.2)$ & 0.419 \\
\hline$\% \mathrm{FT}(\%)$ & $0.207(0.107-0.315)$ & $0.193(0.103-0.298)$ & 0.0588 \\
\hline
\end{tabular}

Median (range). $P$ value was calculated by Mann-Whitney $U$ test. $\mathrm{FT}$, free testosterone; \% FT, percent free testosterone; PSA, prostatespecific antigen; PSAD, PSA density; PV, prostate volume; TT, total testosterone.

http://erc.endocrinology-journals.org https://doi.org/10.1530/ERC-17-0134

(c) 2018 The authors Published by Bioscientifica Ltd. Printed in Great Britain 'bioavailable testosterone' represents the sum of FT plus testosterone bound loosely to albumin. FT represents only $0.5-3 \%$ of TT, but FT is considered the more biologically active form. In Japan, FT values are used in the diagnosis late-onset hypogonadism (LOH) (Namiki et al. 2008).

In young men, FT represents about $2-3 \%$ of TT (De Ronde et al. 2006). As men age, although TT declines (0.4\%/year), FT declines to a greater extent (1.2\%/year) (Swerdloff et al. 2004), resulting in a lower \%FT in older men. In this study, the median age is 69 years (range 35-84) and the median \%FT is $0.21 \%$ (range $0.019-1.27 \%$ ).

The relationship of FT to prostate cancer treatment and outcomes remains largely unexplored, with only a few studies investigating a possible connection (Hoffman et al. 2000, Pierorazio et al. 2010, Garcia-Cruz et al. 2013, Leon et al. 2015). Hoffman and coworkers retrospectively reviewed 117 patients diagnosed with prostate cancer (Hoffman et al. 2000). They reported that all men with a Gleason score of 8 or greater on their prostate biopsy had low free testosterone. They concluded that this finding suggested low serum free testosterone is a marker of more aggressive disease. Leon and coworkers prospectively assessed whether preoperative circulating testosterone levels, obesity and metabolic syndrome were correlated with aggressive pathological features after robotic prostatectomy (Leon et al. 2015). As a result of examining

This work is licensed under a Creative Commons Attribution 4.0 International License. 
A

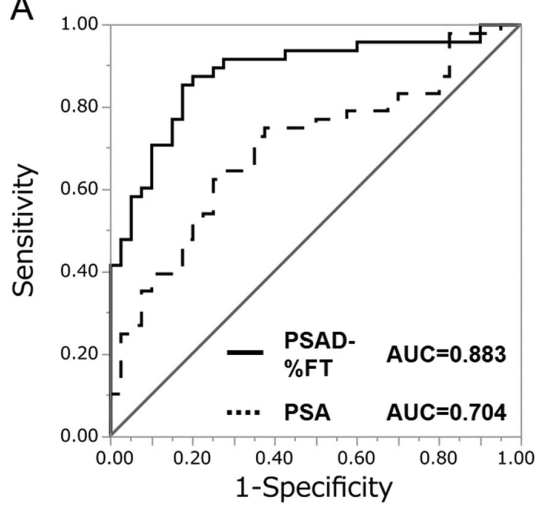

B

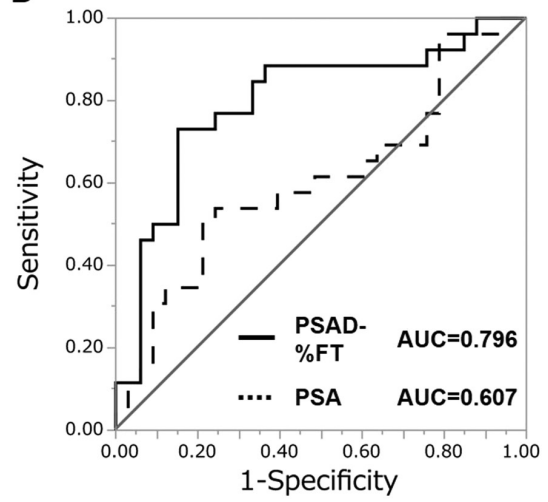

Figure 4

Receiver-operator characteristic (ROC) curves of the predicted probability of prostate cancer detection by the PSAD-\%FT model (solid curves) and PSA (dotted curves) in a testing cohort. (A) ROC curves for all 88 patients. (B) ROC curves for 59 patients with PSA levels under $10 \mathrm{ng} / \mathrm{mL}$.
354 patients undergoing robot-assisted prostatectomy, they concluded that low FT levels were linked with highgrade prostate cancer.

In total, the relationship between prostate cancer risk and absolute androgen concentration remain controversial. In the present study, we focused not only on TT and FT, but also on the FT/TT ratio (i.e., \%FT). A survey of the most current literature includes only one study that examines the utility of \%FT as a predictor for high-grade prostate cancer in men undergoing prostate biopsy (Albisinni et al. 2012). They collected data on 812 white Italian men who underwent prostate biopsy and analyzed the association between prostate biopsy and serum androgen concentrations. They conclude that a greater \%FT level was associated with an increased risk of high-grade prostate cancer (Gleason score $\geq 7$ ), but not low-grade prostate cancer (Gleason score $\leq 6$ ).

Our data show that low \%FT could be a predictor for positive prostate biopsy. These findings suggest that although absolute androgen levels do not modify prostate cancer risk, the free-to-total testosterone ratio could be

Table 6 Patient characteristics in testing cohort with PSA levels under $10 \mathrm{ng} / \mathrm{mL}$.

\begin{tabular}{|c|c|c|c|}
\hline Variables & Negative biopsy & Positive biopsy & $P$ value \\
\hline Number & 33 & 26 & \\
\hline Age (years) & $71(50-81)$ & $72(60-79)$ & 0.515 \\
\hline $\begin{array}{l}\text { PSA (ng/ } \\
\mathrm{mL} \text { ) }\end{array}$ & $5.92(3.55-9.90)$ & $6.99(4.20-9.91)$ & 0.160 \\
\hline PV $(m L)$ & $33.0(17.3-84.8)$ & $25.7(12.9-52.2)$ & 0.014 \\
\hline $\begin{array}{l}\text { PSAD (ng/ } \\
\left.\mathrm{mL} / \mathrm{cm}^{3}\right)\end{array}$ & $0.17(0.06-0.41)$ & $0.25(0.09-0.67)$ & 0.0006 \\
\hline TT (ng/mL) & 3.55 (1.65-7.31) & $3.64(2.03-7.36)$ & 0.541 \\
\hline FT (pg/mL) & $7.9(3.1-16.7)$ & $6.9(3.8-12.8)$ & 0.725 \\
\hline$\%$ FT $(\%)$ & $0.207(0.107-0.315)$ & $0.186(0.126-0.298)$ & 0.0211 \\
\hline
\end{tabular}

Median (range). $P$ value was calculated by Mann-Whitney $U$ test. $\mathrm{FT}$, free testosterone; \% FT, percent free testosterone; PSA, prostatespecific antigen; PSAD, PSA density; PV, prostate volume; TT, total testosterone.

http://erc.endocrinology-journals.org https://doi.org/10.1530/ERC-17-0134

(C) 2018 The authors Published by Bioscientifica Ltd. Printed in Great Britain predictive of positive prostate biopsy. Future studies are needed to address whether \%FT adds meaning to risk stratification for prostate cancer risk and to determine the underlying biologic basis for these results.

Prostate biopsy is the only method to confirm the diagnosis of prostate cancer. Before a prostate biopsy is carried out, it is difficult to discriminate clearly between prostate cancer and benign prostate hyperplasia by PSA values alone. Therefore, several clinical factors and tumor markers have been studied. Some studies reported the utility of Prostate Health Index (Phi) as calculated by ProPSA (Liang et al. 2011, Lazzeri et al. 2012, Bruzzese et al. 2014), prostate cancer gene-3 (PCA3) (Ploussard et al. 2010, Elshafei et al. 2015), gene polymorphisms (Singh et al. 2005, Akamatsu et al. 2012) and multiparametric MRI (Feng et al. 2015, Bergdahl et al. 2016). However, we hoped to develop a quantitative and inexpensive marker in the clinic. We developed a novel predictive model for positive prostate biopsy based on PSAD and \%FT, as derived from readily available PSA, PV, TT and FT values. These values can be measured easily and inexpensively.

In this study, some limitations should be taken into consideration. Firstly, this study consisted of only Japanese patients, and these results might not be applied to other races. Secondly, the number of patients in this study was relatively small. However, we strongly believed that these interesting results can help clinicians in deciding whether prostate biopsy should be carried out, especially for patients with no other evidence than elevated PSA. The true correlation between low levels of $\%$ FT and prostate cancer risk needs validation in large cohort prospective studies.

\section{Conclusion}

Percent-FT (FT/TT ratio), which can be measured easily and inexpensively, was found to be a good predictor of

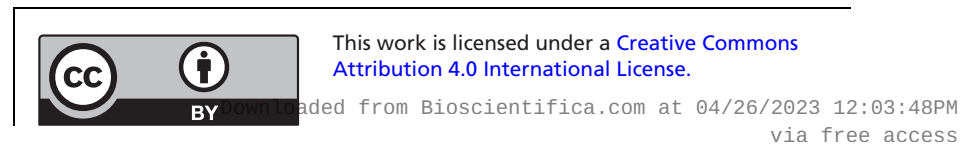


prostate cancer upon prostate biopsy, whereas serum TT and FT values were not. Low \%FT level is an independent risk factor for prostate cancer detection. We were able to construct a novel predictive model based on \%FT and PSAD, which are quantitative factors obtained before prostate biopsy. This model can assist clinicians in deciding whether prostate biopsy is advisable.

\section{Declaration of interest}

The authors declare that there is no conflict of interest that could be perceived as prejudicing the impartiality of the research reported.

\section{Funding}

This research did not receive any specific grant from any funding agency in the public, commercial or not-for-profit sector.

\section{References}

Akamatsu S, Takahashi A, Takata R, Kubo M, Inoue T, Morizono T, Tsunoda T, Kamatani N, Haiman CA, Wan P, et al. 2012 Reproducibility, performance, and clinical utility of a genetic risk prediction model for prostate cancer in Japanese. PLOS ONE 7 e46454. (https://doi.org/10.1371/journal.pone.0046454)

Albisinni S, De Nunzio C, Tubaro A, Barry WT, Banez LL \& Freedland SJ 2012 Greater percent-free testosterone is associated with high-grade prostate cancer in men undergoing prostate biopsy. Urology $\mathbf{8 0}$ 162-167. (https://doi.org/10.1016/j.urology.2012.01.068)

Bergdahl AG, Wilderang U, Aus G, Carlsson S, Dumber JE, Franlund M, Geterud K, Khatami A, Socratous A, Stranne J, et al. 2016 Role of magnetic resonance imaging in prostate cancer screening: a pilot study within the goteborg randomised screening trial. European Urology 70 566-573. (https://doi.org/10.1016/j.eururo.2015.12.006)

Botelho F, Pina F, Figueiredo L, Cruz F \& Lunet N 2012 Does baseline total testosterone improve the yielding of prostate cancer screening? European Journal of Cancer 48 1657-1663. (https://doi.org/10.1016/j. ejca.2012.01.025)

Bruzzese D, Mallarella C, Ferro M, Perdona S, Chiodini P, Perruolo G \& Terracciano D 2014 Prostate health index vs percent free prostatespecific antigen for prostate cancer detection in men with 'gray' prostate-specific antigen levels at first biopsy: systematic review and meta-analysis. Translational Research 164 444-451. (https://doi. org/10.1016/j.trs1.2014.06.006)

De Ronde W, Van der Schouw YT, Pols HAP, Gooren LJG, Muller M, Grobbee DE \& De Jong FH 2006 Calculation of bioavailable and free testosterone in men: a comparison of 5 published algorithms. Clinical Chemistry 52 1777-1784. (https://doi.org/10.1373/ clinchem.2005.063354)

Elshafei A, Chevli KK, Moussa AS, Kara O, Chueh S-C, Walter P, Hatem A, Gao T, Jones JS \& Duff M 2015 PCA3-based nomogram for predicting prostate cancer and high grade cancer on initial transrectal guided biopsy. Prostate 75 1951-1957. (https://doi. org/10.1002/pros.23096)

Feng TS, Sharif-Afshar AR, Smith SC, Miller J, Nguyen C, Li QL, Luthringer D, Li DB, Saouaf R \& Kim HL 2015 Multiparametric magnetic resonance imaging localizes established extracapsular extension of prostate cancer. Urologic Oncology: Seminars and Original Investigations 33 8. (https://doi.org/10.1016/j.urolonc.2014.11.007)

Ferro M, Lucarelli G, Bruzzese D, Di Lorenzo G, Perdona S, Autorino R, Cantiello F, La Rocca R, Busetto GM, Cimmino A, et al. 2017
Low serum total testosterone level as a predictor of upstaging and upgrading in low-risk prostate cancer patients meeting the inclusion criteria for active surveillance. Oncotarget 8 18424-18434. (https://doi.org/10.18632/oncotarget.12906)

Garcia-Cruz E, Piqueras M, Huguet J, Peri L, Izquierdo L, Musquera M, Franco A, Alvarez-Vijande R, Jose Ribal M \& Alcaraz A 2012 Low testosterone levels are related to poor prognosis factors in men with prostate cancer prior to treatment. BJU International 110 E541-E546. (https://doi.org/10.1111/j.1464-410X.2012.11232.x)

Garcia-Cruz E, Carrion Puig A, Garcia-Larrosa A, Sallent A, CastanedaArgaiz R, Piqueras M, Jose Ribal M, Leibar-Tamayo A, Romero-Otero J \& Alcaraz A 2013 Higher sex hormone-binding globulin and lower bioavailable testosterone are related to prostate cancer detection on prostate biopsy. Scandinavian Journal of Urology 47 282-289. (https://doi.org/10.3109/00365599.2012.747562)

Hoffman MA, DeWolf WC \& Morgentaler A 2000 Is low serum free testosterone a marker for high grade prostate cancer? Journal of Urology 163 824-827. (https://doi.org/10.1016/S00225347(05)67812-3)

Huggins C 1942 Effect of orchiectomy and irradiation on cancer of the prostate. Annals of Surgery 115 1192-1200. (https://doi. org/10.1097/00000658-194206000-00030)

Klap J, Schmid M \& Loughlin KR 2015 The relationship between total testosterone levels and prostate cancer: a review of the continuing controversy. Journal of Urology 193 403-413. (https://doi. org/10.1016/j.juro.2014.07.123)

Lazzeri M, Briganti A, Scattoni V, Lughezzani G, Larcher A, Gadda GM, Lista G, Cestari A, Buffi N, Bini V, et al. 2012 Serum index test \% -2 proPSA and prostate health index are more accurate than prostate specific antigen and \%fPSA in predicting a positive repeat prostate biopsy. Journal of Urology 188 1137-1143. (https://doi.org/10.1016/j. juro.2012.06.017)

Leon P, Seisen T, Cussenot O, Drouin SJ, Cattarino S, Comperat E, Renard-Penna R, Mozer P, Bitker M-O \& Roupret M 2015 Low circulating free and bioavailable testosterone levels as predictors of high-grade tumors in patients undergoing radical prostatectomy for localized prostate cancer. Urologic Oncology: Seminars and Original Investigations 33 384.e21-384.e27. (https://doi.org/10.1016/j. urolonc.2014.11.010)

Liang Y, Ankerst DP, Ketchum NS, Ercole B, Shah G, Shaughnessy JD, Leach RJ \& Thompson IM 2011 Prospective evaluation of operating characteristics of prostate cancer detection biomarkers. Journal of Urology 185 104-110. (https://doi.org/10.1016/j.juro.2010.08.088)

Mohr BA, Feldman HA, Kalish LA, Longcope C \& McKinlay JB 2001 Are serum hormones associated with the risk of prostate cancer? Prospective results from the Massachusetts Male Aging Study. Urology 57 930-935. (https://doi.org/10.1016/S00904295(00)01116-X)

Morote J, Ramirez C, Gomez E, Planas J, Raventos CX, de Torres IM \& Catalan R 2009 The relationship between total and free serum testosterone and the risk of prostate cancer and tumour aggressiveness. BJU International 104 486-489. (https://doi. org/10.1111/j.1464-410X.2009.08378.x)

Mottet N, Bellmunt J, Bolla M, Briers E, Cumberbatch MG, De Santis M, Fossati N, Gross T, Henry AM, Joniau S, et al. 2016 EAU-ESTRO-SIOG guidelines on prostate cancer. Part 1: screening, diagnosis, and local treatment with curative intent. European Urology 16 30470-30475. (https://doi.org/10.1016/j.eururo.2016.08.003)

Namiki M, Akaza H, Shimazui T, Ito N, Iwamoto T, Baba K, Kumano H, Koh E, Tsujimura A, Matsumiya K, et al. 2008 Clinical practice manual for late-onset hypogonadism syndrome. International Journal of Urology 15 377-388. (https://doi. org/10.1111/j.1442-2042.2008.02010.x)

Pierorazio PM, Ferrucci L, Kettermann A, Longo DL, Metter EJ \& Carter HB 2010 Serum testosterone is associated with aggressive prostate cancer in older men: results from the Baltimore
() 2018 The authors Published by Bioscientifica Ltd. Printed in Great Britain
This work is licensed under a Creative Commons Attribution 4.0 International License. 
Longitudinal Study of Aging. BJU International 105 824-829. (https://doi.org/10.1111/j.1464-410X.2009.08853.x)

Ploussard G \& de la Taille A 2010 Urine biomarkers in prostate cancer Nature Reviews Urology 7 101-109. (https://doi.org/10.1038/ nrurol.2009.261)

Porcaro AB, Petrozziello A, Romano M, Sava T, Ghimenton C, Caruso B, Migliorini F, Antoniolli SZ, Rubilotta E, Lacola V, et al. 2010 Investigative Clinical Study on Prostate Cancer Part III: exploring total PSA and free testosterone distributions and linear correlations in groups and subgroups of operated prostate cancer patients according to the total PSA/FT ratio. Urologia Internationalis $\mathbf{8 5}$ 406-409. (https://doi.org/10.1159/000319966)

Porcaro AB, Siracusano S, De Luyk N, Corsi P, Sebben M, Tafuri A, Bizzotto L, Tamanini I, Inverardi D, Cerruto MA, et al. 2016 Low-risk prostate cancer and tumor upgrading to higher patterns in the surgical specimen. Analysis of clinical factors predicting tumor upgrading to higher Gleason patterns in a contemporary series of patients who have been evaluated according to the modified Gleason score grading system. Urologia Internationalis 97 32-41. (https://doi.org/10.1159/000445034)

Porcaro AB, De Luyk N, Corsi P, Sebben M, Tafuri A, Processali T, Cerasuolo M, Mattevi D, Cerruto MA, Brunelli M, et al. 2017 Association between basal total testosterone levels and tumor upgrading in low and intermediate risk prostate cancer. Urologia Internationalis 99 215-221. (https://doi.org/10.1159/000459632)

Regis L, Planas J, Celma A, de Torres IM, Ferrer R \& Morote J 2015 Behavior of total and free serum testosterone as a predictor for the risk of prostate cancer and its aggressiveness. Actas Urologicas Espanolas 39 573-581. (https://doi.org/10.1016/j.acuro.2015.03.004)

Rosner W, Auchus RJ, Azziz R, Sluss PM \& Raff H 2007 Position statement: utility, limitations, and pitfalls in measuring testosterone: an endocrine society position statement. Journal of Clinical
Endocrinology and Metabolism 92 405-413. (https://doi.org/10.1210/ jc.2006-1864)

Rove KO, Crawford ED, Perachino M, Morote J, Klotz L, Lange PH, Andriole GL, Matsumoto AM, Taneja SS, Eisenberger MA, et al. 2014 Maximal testosterone suppression in prostate cancer-free vs total testosterone. Urology 83 1217-1222 (https://doi.org/10.1016/j. urology.2014.02.001)

Shaneyfelt T, Husein R, Bubley G \& Mantzoros CS 2000 Hormonal predictors of prostate cancer: a meta-analysis. Journal of Clinical Oncology 18 847-853. (https://doi.org/10.1200/JCO.2000.18.4.847)

Shin BS, Hwang EC, Im CM, Kim SO, Jung SI, Kang TW, Kwon DD, Park K \& Ryu SB 2010 Is a decreased serum testosterone level a risk factor for prostate cancer? A Cohort Study of Korean Men. Korean Journal of Urology $\mathbf{5 1}$ 819-823. (https://doi.org/10.4111/ kju.2010.51.12.819)

Singh AS, Chau CH, Price DK \& Figg WD 2005 Mechanisms of disease: polymorphisms of androgen regulatory genes in the development of prostate cancer. Nature Clinical Practice Urology 2 101-107. (https://doi.org/10.1038/ncpuro0091)

Swerdloff RS \& Wang C 2004 Androgens and the ageing male. Best Practice and Research Clinical Endocrinology and Metabolism 18 349-362. (https://doi.org/10.1016/j.beem.2004.03.011)

Tu H, Gu J, Meng QH, Kim J, Strom S, Davis JW, He YG, Wagar EA, Thompson TC, Logothetis CJ, et al. 2017 Low serum testosterone is associated with tumor aggressiveness and poor prognosis in prostate cancer. Oncology Letters 13 1949-1957. (https://doi.org/10.3892/ ol.2017.5616)

Yano M, Imamoto T, Suzuki H, Fukasawa S, Kojima S, Komiya A, Naya Y \& Ichikawa T 2007 The clinical potential of pretreatment serum testosterone level to improve the efficiency of prostate cancer screening. European Urology 51 375-380. (https://doi.org/10.1016/j. eururo.2006.08.047)

Received in final form 10 October 2017

Accepted 18 October 2017

Accepted Preprint published online 18 October 2017
() 2018 The authors Published by Bioscientifica Ltd. Printed in Great Britain
This work is licensed under a Creative Commons Attribution 4.0 International License. 